\title{
EL PADECER COMO SUSTENTO TRÁGICO EN LA PEDAGOGÍA HERMENÉUTICA DE H.-G. GADAMER
}

\author{
Joaquín ESTEBAN ORTEGA \\ Universidad de Valladolid
}

\begin{abstract}
RESUMEN. Llevar hasta sus últimas consecuencias la filosofía de la finitud implícita en el pensamiento gadameriano nos permite esclarecer la rałz trágica de la educación. El presente trabajo propone concebir, desde la filosofía de Gadamer, una pedagogía hermenéutica del padecimiento que excluya de raíz toda ingenuidad pedagógica y que ofrezca un soporte ontológico radical a las corrientes educativas que se vienen apoyando en los planteamientos del filósofo alemán.
\end{abstract}

De forma ejemplar se podría decir que la educación es una de las instituciones que está atravesando más explícitamente todo el proceso de transformación cultural en el que nos vemos envueltos. Son muchos los aspectos sobre los que habría que incidir para corroborar esta afirmación, sin embargo podríamos simplemente señalar uno de especial importancia a partir del cual comenzar a gestar el hilo discursivo del presente trabajo.

Hemos ido viendo en estos últimos tiempos cómo la dinamización histórica de la verdad ha hecho que se pusiera en cuestión la unidireccionalidad del saber que tan bien ha guardado la escuela tradicional. A ésta, en contrapartida, se le ha venido otorgando la adecuada vertebración epistemológica para legitimar una estructura disciplinaria y de poder con la que mantener alejado el fantasma del debilitamiento ideológico a lo largo de los siglos. Esta circunstancia ha ido provocado la progresiva y oportuna reacción de un rescate ontológico de la adormecida potencialidad de la memoria y, con ella, el que una revitalizada subjetividad, sustraída de cualquier juego atemporal y metafísico, se haya visto envuelta en ese conflicto hermenéutico de interpretaciones abierto desde la apertura misma del sentido. El sujeto lector se recupera a sí mismo gracias a la inquietante 
urgencia de activar mecanismos creativos de mediación más allá de los sometimientos de una orgullosa objetividad científica. Entre otras muchas consecuencias culturales este contexto ha empezado a cuestionar y poner en evidencia los esquemas impositivos y disciplinarios de socialización y de transmisión del saber a pesar de todas las resistencias. En este sentido, reactivar el discurso narrativo y retórico implícito en la extensión educativa de la experiencia hermenéutica nos parece, sin duda, que tiene claras consecuencias prácticas sobre un êthos pedagógico contemporáneo especialmente instrumentalizado por la tecnología social y psicopedagógica y por las interesadas coyunturas del mercado.

Ahora bien, no podremos discurrir, por todo lo dicho, a través de algún nuevo tipo de ideal educativo con el que reproducir los esquemas metafísico-educativos de los que partimos. La aspiración del presente trabajo es la de poner de manifiesto la ineludible dimensión trágica de la que ha de brotar toda experiencia hermenéutico-educativa por su propio modo de ser; la de no quedar aturdidos por el anonadamiento inconsciente del carácter terapéutico de la educación. El espíritu que anima nuestra intuición se sustenta en la idea de que es muy difícil seguir arrancando de la perspectiva utópica y emancipadora de lo educativo (si acaso podrá seguir siendo un legítimo punto de llegada) después de reconocer para nuestros días los determinantes de la finitud y de la historicidad humana; es decir, que difícilmente la época postmetafísica puede ofrecer un ideal de humanidad sobre el que proyectar una nueva violencia de fundamentación mediante la cual disponer con carácter previo todos los juegos de organización hacia los que ha de tender una sociedad no especialmente marcada hoy por los rasgos de la férrea identidad y de la convergencia cultural. Por eso creemos que no nos es posible sustraernos de la implicación ontológica que se encuentra en el conatus de la educación. El pensamiento de Gadamer será nuestra guía, sin embargo al principio será preciso salir de él de forma tentativa para atravesar el sendero trágico del nihilismo ontológico con objeto de poder retornar a él, habiendo ya tocado fondo, para recuperar sin ingenuidades el verdadero potencial crítico y existencial que encierra la memoria hermenéutico-educativa para nuestro presente. De algún modo esta suerte de epoché que la hermenéutica realizará sobre sí misma nos permitirá seguir recordando el carácter quebradizo e inacabado de la procesualidad del sentido sobre la que lo educativo no tiene más remedio que transitar de forma inapelable.

Los pasos que recorreremos en este camino serán, en primer lugar, constatar cómo para que la Bildung que Gadamer rescata de la tradición humanista nos 
pueda ofrecer en toda su extensión el sustento formativo de la temporalidad phronética como verdadero hilo conductor de la experiencia educativa será necesario evidenciar los inconvenientes que para nuestros planteamientos encierra su raigambre idealista. Para ello recurriremos a las posibilidades que nos ofrece el nihilismo filosófico de Vattimo al radicalizar la dimensión retórico-narrativa de la memoria en su ontología hermenéutica del declinar. Tras ello, nos encontraremos en mejor disposición para extraer las oportunas consecuencias de los conceptos de lectura y êthos dialógico de la pedagogía gadameriana del padecer a través de la presentación de algunos presupuestos actuales sobre el asunto.

\section{Bildung: êthos pedagógico y lastres metafísicos}

No nos detendremos aquí en si Bildung ha de identificarse prioritariamente con la noción de formación o de cultura. El ámbito semántico pedagógico que nos interesa ciertamente encierra las dos acepciones en tanto que la formación únicamente se realiza desde el soporte de la cultura; o dicho de otro modo, en tanto que es la cultura la que se realiza a sí misma como memoria internalizada y como prácticas e instituciones transmitidas. En todo caso resulta bastante claro que este presupuesto nos sitúa espontáneamente ante la noción hermenéutica de pertenencia.

Un aspecto crítico que encontramos en la obra de Vattimo con respecto a Gadamer es el referido expresamente a este concepto de Zugehörigkeit. Como se sabe, de raigambre hegeliana, este concepto es eje vertebral de su rehabilitación de la tradición, de su noción más original de "historia efectual" y, en definitiva, de su concepción hermenéutica de la memoria. En él se nos quiere hacer ver que la filosofía no se puede reducir a un acto de la razón y que por tanto no se puede alcanzar la aspiración absoluta de la autoconciencia. La pertenencia supone que la conciencia está siempre dentro de la realidad. Pues bien, para Vattimo, si este discurso no termina en la ratificación del espíritu absoluto, no se sabe bien cuál es su sentido ${ }^{1}$ Quizás Vattimo no haga del todo justicia al hecho de que este concepto de pertenencia es el que verdaderamente posibilita la introducción de una esencial dimensión práctica en la Bildung ${ }^{2}$. Sólo porque se pertenece a una

1 Cf. G. VATTIMO, Vocazione e responsabilità del filosofo, Génova, Il Melangolo, 2000, p. 59.

${ }^{2}$ Muy esclarecedor en este sentido resulta el trabajo de C. LOPEZ SAEZ "La importancia de la Bildung para la culturam, en LINARES Y SANCHEZ (eds.), Actas del IV Congreso Internacional de la SHAF, Universidad de Valencia, 2001, pp. 743-749. 
tradición, el phrónimos es capaz de aprender lo que es correcto en cada caso. Sin embargo, al margen de que muchos autores hayan visto en esta concepción un determinismo historicista y reproduccionista desde el cual resulta imposible cualquier opción transformadora o emancipadora de las cosas o de la realidad, esto no es obstáculo para que ya esté bien resuelto el hecho de que en la esencia de la acción del prudente se encuentra la capacidad crítica de la deliberación (proairesis) y de que ello resulta ser de un valor esencial en los procesos socioeducativos contemporáneos tan condicionados por la instrumentalidad del saber.

De todos modos, no podemos dejar de tener en cuenta la crítica general de base que Vattimo realiza en la medida en que la pertenencia, aunque Gadamer quiera sustraerse decididamente de ello, cuando termina desdibujando los límites entre la razón y la realidad en su más íntimo dinamismo, está ofreciendo un soporte apropiado a ese concepto clásico de Bildung o de Paideia a través del cual se nos hace ver que la formación impulsa una promoción pedagógica y cultural de los valores del espíritu humano globalmente considerados, tal y como quedaría reflejado en los primeros momentos de desarrollo histórico del concepto ${ }^{3}$. $Y$ es que precisamente la Bildung que rescata Gadamer de la tradición clásica es la que ha servido de manera más eficiente a la ratificación de todo tipo de idealismo humanista y pedagógico. Cualquier pretensión de sustraerse de ello requiere tematizar en alguna medida el problema de la escisión.

\section{La relectura debilitada de la experiencia hermenéutico-educativa}

La emblemática pretensión gadameriana de reducir la escisión entre método o ciencia y verdad no es, en el fondo, una cuestión epistemológica sobre la verdad o la falsedad de las proposiciones científicas, sino más bien un claro asunto de carácter social. Ahora bien, Gadamer no ha radicalizado la implicación metafísica del continuo proceso actual de instrumentalización técnica de la ciencia. Como piensa Vattimo, a pesar de que efectivamente en Gadamer hay un enfrentamiento crítico con el objetivismo científico, no se da en el discípulo de Heideg-

${ }^{3}$ Véase C. VIlanou, «Formación, cultura y hermenéutica. De Hegel a Gadamer», en Revista de Educación, 328 (2002) 205-223; J. M. ' QUINTANA CABANAS, "El concepto de formación (Bildung) en el pensamiento alemánn, en Teoria de la Educación. Concepción antinómica de la educación, Madrid, Dykinson, 1995, pp. 33-45. 
ger la pretensión de una verdadera historia del ser; antes bien, su "pretendido" humanismo le acerca mucho más a la tradición esencialista clásica. Esto es lo que hace que, más cercano a Heidegger, Vattimo vea en la ciencia un aspecto del «destino" del ser en la época contemporánea, es decir, el modo en que hoy se ha radicalizado la diferencia ontológica y, por tanto, la vocación nihilista de la filosofía.

Nos interesa ahora esta conocida perspectiva del filósofo italiano en la medida en que si el enfrentamiento humanista y hermenéutico de Gadamer con la objetivación cientifista de la realidad resulta ser él mismo una reivindicación metafísica parecería claro que el saber quedaría sometido a una suerte de unidireccionalidad gnoseológica que en nada favorecería a la dimensión phrónica de un concepto clave de la pedagogía hermenéutica como es el de Bildung. De este modo, nos es preciso destacar que la perspectiva débil de la ontología puede permitirnos tocar fondo ya que si la memoria deja de tener el menor atisbo de conservadurismo sustancial para ofrecerse como permanente despedida del acontecer del ser, parece que puede permitir con más facilidad el estallido real de la diferencia y de la fragmentación histórica de sentido que reclama la hermenéutica para sí. De este modo, se rompen los discursos lineales del saber asignaturístico tan marcado por una ordenación metafísica de la institución y estructura educativa. Del mismo modo, se modifica la estrategia de aprendizaje a partir del juego dialógico implícito en una didáctica de la limitación y siempre presente en el preguntar.

El debilitamiento hermenéutico de la ontología implica, por tanto, ese aspecto trágico que le interesa a una pedagogía del padecimiento en toda su extensión. Si el punto de partida es la ingenuidad positiva de la esperanza educativa de un ideal de ser humano marcado por unos determinados valores preestablecidos por la inercia endurecida de la tradición, el resultado es la reducción inconsciente de la ilustración a mera terapia contra el dolor y la finitud. Sin embargo, esta reformulación trágica del nihilismo ontológico débil (quizás no desarrollada en toda su extensión por el propio Vattimo) nos permite realizar un ejercicio de reducción hermenéutica sobre la propia experiencia educativa.

Recordemos que Vattimo dejó caracterizadas de forma emblemática las claves del pensamiento débil al afirmar que en él se sintetiza una distorsión y un sobreponerse de la metafísica sin prescindir de ella (Verwindung), que en él se manifiesta un talante ultrametafísico y rememorante del ser siempre aconteciendo 
pero siempre ausente (An-Denken) y que, como extensión de lo anterior y especialmente significativo para nosotros, que en él se actualiza una pedagogía de la huella de lo que fue vivo, de la Pietas. Con la pietas se evoca la mortalidad, la finitud y la caducidad ${ }^{4}$. «El verdadero trascendental —señala Vattimo-, lo que hace posible cualquier experiencia del mundo es la caducidad ${ }^{5}$. Sólo porque el ser su-cede (ac-cadere) y no porque sea, es por lo que el mundo se abre al sentido. Este es el motivo de que cualquier experiencia tenga que ver con la ausencia $y$, por tanto, con el inacabamiento permanente e implícito de toda rememoración. "Recordar el ser - continúa Vattimo - equivale a traer a la memoria esta caducidad; el pensamiento de la verdad no es un pensamiento que 'fundamenta', tal como piensa la metafísica, incluso en su versión kantiana, sino, al contrario, es aquel pensamiento que, al poner de manifiesto la caducidad y la mortalidad como constitutivos intrínsecos del ser, lleva a cabo una des-fundamentación o hundimiento (sfondare)" ${ }^{6}$.

Se podría decir que la experiencia educativa es, en este sentido, paradigma de una ontología del declinar en la medida en que carecer de la terapéutica "presencia» del ser $y$, por tanto, de la violencia del saber disciplinar, positivo y cosificable del encubrimiento, reotorga al ser humano el constitutivo estado de incertidumbre sobre el que volcar de forma narrativa las urgencias temporales de su limitación y el inacabamiento abierto de su lectura del mundo. La educación así pierde su sustento metafísico porque reclama la originariedad de su dimensión retórica.

Ganada la expectativa trágica, y por extensión nihilista, para la experiencia educativa nos situamos ante una perspectiva hermenéutica en la que como vemos el lenguaje se desvela retóricamente como el único lugar posible donde gestionar la complejidad de nuestra existencia. Es en el lenguaje, que originariamente se anticipó como grito ante el vértigo del devenir ${ }^{7}$, donde se especifica el dolor y el límite de querer seguir siendo, de tener que educar para permanecer y de ser educados para interpretar irremisiblemente otorgando algún sentido provisional

4 Cf. G. VATtimo, "Dialéctica, diferencia y pensamiento débil», en G. VATTIMO y P. A. RovaTI (eds.), El pensamiento débil, trad. cast. L. de Santiago, Madrid, Cátedra, 1988, p. 33.

5 lbid., p. 34.

6 Ibid., p. 34.

${ }^{7}$ Cf. E. Severino, El parricidio fallido, trad. cast. F. Bassots, Barcelona, Destino, 1991, pp. 53 y ss. 
al deseo de permanencia. Vattimo manifiesta también estas intuiciones al señalar que "las experiencias nuevas que hacemos tienen sentido sólo en cuanto prosiguen el diálogo con cuanto el cofre de la muerte - la historia, la tradición y el lenguaje - nos ha transmitido" ${ }^{8}$. Sin duda, habría que extraer en toda su extensión y complejidad las consecuencias de aplicar esta consideración del pensamiento débil para la filosofía, en el sentido de no poder ni deber enseñar a dónde nos dirigimos sino a vivir en la condición de quien no se dirige a ninguna parte ${ }^{9}$. La cuestión fundamental es la de ver cómo puede darse de hecho el declinar y la torsión del carácter normativo de la educación, siempre ineludible, más allá de la configuración normativo-metafísica tradicional. Probablemente la constitutiva normatividad pedagógica que se abra desde una experiencia hermenéutica filtrada por la experiencia desalienante del dolor y de la siempre expectante despedida encierra un tipo de normatividad para lo educativo en la que la utopía ya no ha de cargarse dialéctica o espiritualmente de ideología sino de ausencia y, por tanto, de diferencia y de la ilusión de no tener que tener ilusiones. A nuestro entender, con esta beligerante negativa a establecer un vertebrador télos determinado al que dirigir la historia, es decir la acción humana y con ella la acción educativa, la memoria gana el futuro justamente en el mismo momento de perderlo. Se consigue así una reconsideración de la autonomía absolutamente radicalizada. La hermenéutica nihilista implica de este modo una verdadera voluntad de poder como arte formativo y, por lo mismo, un sutil desvanecimiento de las fronteras entre la estética y la educación. Esta voluntad de poder del pensamiento débil es fuerte porque es la voluntad de la carencia, la de quien tiene menesteres ${ }^{10}$. Esto significa que es precisamente en el reconocimiento de las demarcaciones de la vida donde se genera el impulso vital; sólo al tocar el fondo trágico del debilitamiento nihilista reacciona nuestra auténtica necesidad de permanecer y de ser transmitidos, sólo cuando el pensamiento es hermenéutica conseguimos dar forma a la proyección siempre abierta de la carencia de sentido, sólo cuando queda el saber y sus extensiones culturales sustraídas del dogma de la fundamentación conseguimos activar ontológicamente una verdadera estética de la acción educativa.

${ }^{8}$ G. Vattimo, Más allá del sujeto, trad. cast. J. C. Gentile, Barcelona, Paidós, 1992, 2. ${ }^{a}$ ed., p. 12.

${ }^{9}$ Cf. ibid., pp. 11-12.

${ }^{10}$ Ll. Álvarez, "Introducción» a G. VATTIMO, Filosofia, Politica, Religión. Más allá del pensamiento débil, Oviedo, Nobel, 1996, p. 14. 
La pedagogía, por todo ello, cede y se despide lentamente de esa pretensión instrumental en la que han derivado las ciencias de la educación, sustentadas a su vez por la derivación técnica de la diferencia ontológica, con objeto de ganar un êthos retórico en el que, como advertíamos, no quede más remedio que narrar la incertidumbre. De igual forma la educativa ya no tendrá que ser esa institución obediente a los endurecimientos fundamentadores, pudiendo reconsiderar su sometimiento a principios "ponentes» como el de igualdad o justicia mediante ideales «deponentes» como los de la reducción de la violencia (Vattimo) y el de la lealtad (Rorty) ${ }^{11}$.

Únicamente tras la reducción del filtro ontológico del debilitamiento trágico podemos situarnos en el espacio de la pedagogía hermenéutica al ser ahora considerada más como punto de llegada que como punto de partida. La hermenéutica no sólo es un camino o un método, tal y como nos hizo ver la tradición clásica, sino un modo de ser. En este sentido es en el que nosotros hablamos de punto de llegada; es decir, en cuanto manera constitutiva de ser. Ahora bien, lo que nosotros queremos evidenciar es que la apertura histórico temporal en la que se nos instala tras el desbloqueo metódico de la memoria no tiene por qué ser necesariamente y a priori una apertura esperanzada. Las posibilidades educativas, éticas y críticas que como veremos implica el hecho de que el lenguaje esté íntimamente vinculado con el fenómeno de la comprensión, no significan que la proyectividad del seguir siendo en la memoria tenga que abrir un espacio de futuro siempre lleno de contenido y liberación. El debilitamiento ontológico nos ha enseñado que el verdadero punto de partida al reconocernos con el ser como tiempo en nuestra finitud y en la retirada ausente de nuestra presencia implica un contenido trágico para la experiencia hermenéutico-educativa. $\mathrm{Si}$, como señalábamos, la única ilusión posible es la de no tener ilusiones, es precisamente ese padecimiento sobre nuestra contingencia el que nos puede permitir esclarecer y

11 No podemos decir que tengamos que empezar de cero. El cambio social considerado desde un punto de vista educativo nos está haciendo ver cómo se ha producido un incremento significarivo en el ámbito de la educación no formal. El pluralismo, la fragmentación de los discursos y de las prácticas y su reconocimiento ha hecho que la formación reclame todos los espacios divergentes de tolerancia en el desarrollo de la diferencia. Los cimientos modernos de la escuela formal están queriendo ser dinamizados también, aunque básicamente obedeciendo a estrategias dirigidas de emancipación, a conveniencias del mercado y a la coyuntura tecnoinformativa en la que la ha situado la tardomodernidad. 
liberar la potencialidad de los conceptos esenciales de la filosofía de Gadamer para el ámbito educativo. Únicamente si rebajamos de partida las pretensiones metafísicas del ideal humanista que encierra su propuesta podremos reducir el optimismo terapéutico propio de la acción educativa. Sólo la radicalización de una filosofía de la finitud, sustraídos de cualquier fundamentación sobre lo que el ser humano deba ser a través de su formación, permitirá la radicalización de la diferencia y con ella de una idea sólida y auténtica de tolerancia. Es sólo si se entiende la lingüisticidad como momento de llegada tras tocar fondo, cuando podremos extraer las consecuencias adecuadas para el ámbito educativo de la dialéctica dialógica de pregunta-respuesta, de la rehabilitación de los conceptos de tacto, autoridad y tradición, de la reivindicación práctica de una acción mesurada en cada caso mediante un ejercicio de virtud moral, de leer e interpretar de forma ineludible la dinamicidad de lo real a la que pertenecemos, etc.

Rigurosamente hablando no hay filosofía alguna que no comporte una dimensión trágica que atraviese todos sus presupuestos. Incluso los optimismos filosóficos, bien sean humanistas o teológicos, encierran en sí mismos esa terapéutica de la esperanza que por defecto nos remite expresamente a nuestra propia limitación y al sufrimiento. Recordemos a Epicuro cuando afirmaba que «vana es la palabra del filósofo que no remedia ningún sufrimiento humano», o cuando Nietzsche manifestaba sus reticencias con respecto a aquellas filosofías incapaces de ofrecer sentido al dolor vital. En su caso expresamente el sufrimiento ofrece, por una parte, la dignidad heroica de aquél que soporta y lucha frente a la adversidad sin resentimientos; $y$, por otra, el espectáculo soberbio de la vida afirmándose en cada grito y en cada desgarro.

La pedagogía hermenéutica, en este mismo sentido, ha de ser considerada como paradigma de este espíritu trágico olvidado por el dolor. En la permanente inquisición semántica sobre el mundo y sobre los otros, cultural y dialógica, subyace siempre la inoperatividad y el desencanto. Es la mortalidad la que anima el fenómeno de la interpretación, la que nos sujeta y la que nos interpela ya que nada le es propio a nuestra indefinición ${ }^{12}$. Reformular este pesimismo hermenéutico, siempre latente a pesar de toda aquella pretensión ilustrada, es redu-

12 J. C. MELLICH en su libro Filosofia de la finitud, Barcelona, Herder, 2002, pp. 46 y ss., ratifica esa opinión de Odo Marquard sobre el hecho de que la hermenéutica responde a la caducidad y a la finitud humanas. 
cir al máximo la autocompasión con la que pretendemos contarnos el modo en que queremos ser y los juegos institucionales a través de los cuales llevarlo a cabo. La carga crítica que encierra este pesimismo hermenéutico es, a nuestro entender, mucho más convulsionante que todas las propuestas teleológicas de emancipación, ya que no obvia en ningún caso el reconocimiento auténtico de uno mismo y de la carencia implícita de la alteridad. Al hacerlo se está reclamando un pedagogo crítico que desenmascare las formas de producirse los discursos en el momento mismo de transmitir la presencia inquietante de la finitud ${ }^{13}$.

\section{Pedagogía hermenéutica del padecimiento}

Hasta ahora hemos podido percibir que el proceso de descentramiento obrado desde la filosofía hermenéutica se desmarca progresivamente de cualquier pretensión de certidumbre preventiva y analgésica que especifique de forma lineal la dirección adecuada de la acción. En general, la acción educativa, en tanto que acción humana, pudiera dar la impresión de que obedece a una intención reductiva y simplificadora ya que ante la alternativa de la elección siempre surge la opción concreta, sin embargo, en la decisión se conserva la apuesta, el riesgo y la incertidumbre. Recordemos, en este sentido, cómo los filósofos existencialistas reconocían el carácter dramático de la libertad. Pues bien, del mismo modo, la ejecutividad de la acción educativa está atravesada por el dinamismo de la imaginación y por el amplio número de decorados posibles sobre los que enmarcar la toma de decisiones y la consecuente modificación misma de la acción en su ejercicio. Por eso la acción se escapa a nuestras intenciones y supone complejidad, azar e incertidumbre.

Los autores más significativos del pensamiento complejo, a la hora de enfrentarse con el carácter aleatorio de la acción, nos hablan más de estrategias que de programas $^{14}$. En este sentido, si en el contexto didáctico seguimos entendiendo la programación desde un paradigma simplificador de la acción, de la narración y de la experiencia educativa, y desde la estabilidad intencional de los presupuestos impositivos de la disciplinariedad curricular, habremos de convenir que nuestras

${ }^{13}$ Cf. ibid., pp. 51-52.

${ }^{14}$ Cf. E. Morin, Introducción al pensamiento complejo, trad. cast. M. Packman, Bardelona, Gedisa, 2001, p. 115. 
prácticas continúan estando aún sustentadas por la unilineal neutralización disciplinaria de la cual el manual escolar se convierte en simbólico garante.

La acción, al ser contada y por tanto al ser ejecutada, para que se convierta en experiencia educativa auténtica, es decir, en experiencia hermenéutica, ha de gestionar lo imprevisible de forma estratégica. Ante lo inesperado, ante la eventualidad de cada uno de los acontecimientos, la respuesta pasa por el prudente acondicionamiento de lo más oportuno, por la reivindicación de la sutileza aplicativa, tal y como nos ha mostrado Gadamer. El riesgo de cualquier decisión en el que se enmarca la gestión de la finitud y de lo incierto, conscientemente desterrado por el optimismo reductivo de la epistemología moderna, es el que nos permite reintroducir la energía del sufrimiento de forma positiva. Incluso algunas extensiones sistémicas del pensamiento complejo, atravesadas por la incertidumbre, al jugar con la ventaja de concebir la sociedad sin hombres (Luhmann) o con hombres simbióticos (Joël de Rosnay), se han dejado seducir paradójicamente por la urgencia de la satisfacción de deseo. Antoni Colom, en este mismo contexto y en un trabajo sobre la educación en la sociedad red, piensa que la transformación posible de la escuela pasa por la síntesis entre el saber y el placer. Expresamente dice: «Debemos ir hacia una escuela hedonista, una escuela del placer, (...) del goce, donde el deseo sea satisfecho y donde la sensualidad adquiera la categoría de conocimiento" ${ }^{15}$. Sin duda, una ludoescuela de este tipo es la extensión más paradigmática del adormecimiento de la paideía en nuestra cultura contemporánea. La red debe satisfacer el deseo en la escuela de forma automática para ejercer, con una apariencia casi naïve, un violento olvido del sufrimiento y de la contingencia. No obstante, otros autores, pensemos por ejemplo en E. Morin, que perciben en la incertidumbre el motor del saber al margen de este optimista velo pedagógico, han destacado en numerosas ocasiones la dimensión trágica, y por tanto retórica, del conocimiento y de la complejidad.

Podríamos decir en este sentido, y al hilo de la presente reflexión, que la columna vertebral de la hermenéutica gadameriana a la vez que se ha instalado en la reticencia explícita sobre la unidimensionalidad metódica, nos ha propuesto

15 A. J. COLOM, «La educación en la sociedad red», en A. ESCOLANO y J. M. HERNANDEZ (coords.), La memoria y el deseo. Cultura de la escuela y educación deseada, Valencia, Tirant lo Blanch, 2002, pp. 336-337. 
otro modo propio de gestionar la incertidumbre al reivindicar la experiencia dinámica de la verdad en ámbitos en los que conscientemente había sido excluida. Sólo a partir de tales constataciones Gadamer pudo situar la riqueza creadora del ejercicio de la experiencia de finitud en la incertidumbre temporal del ser humano. Por ello, con tremenda oportunidad, rescató en su obra esencial Verdady método el páthei máthos que anunciara Esquilo en su Agamenón $n^{16}$ : aprender del padecer y a padecer, es la creativa consecuencia de introducir la incertidumbre en la acción y en la educación.

Como ha venido señalando Emanuele Severino ${ }^{17}$, antes de brindársenos el fármaco de la metafísica y de la ciencia-tecnología como respuesta adormecedora a nuestra finitud e incertidumbre, Esquilo consiguió ofrecer la primera gran autentificación temática de una pedagogía del padecimiento. $\mathrm{Al}$ instalarse resueltamente en la creencia de que todo ente, incluido el ser humano, proviene de la nada y a la nada retorna, el trágico griego consiguió que el grito originario de la existencia se convirtiera en palabra y la palabra en paideia ilusionante. La diferencia que hay entre Severino y Gadamer en este asunto es que el primero con estas descripciones quiere ratificar la historia de un error, esto es, el de la creencia en el devenir, mientras que para Gadamer lo que hacemos al rescatar este $p a^{-}$ thos educativo es precisamente dar cuenta sincera de nuestra condición sin tomar como referencia la eternidad de todo ente o cualquier otra absolutización de lo real.

Las páginas que Gadamer dedica en Verdad y método a la cuestión de la finitud son, a nuestro entender, la auténtica raíz del pensamiento de su autor a pesar de que sus múltiples discursos tiendan a obviar y a desdibujar su verdadera importancia. «Lo que el hombre aprenderá por el dolor — señala Gadamer — no es esto o aquello, sino la percepción de los límites de ser hombre, la comprensión de que las barreras que nos separan de lo divino no se pueden superar» (VM. 433). Únicamente la memoria siempre escindida de la educación nos permite reparar los otros motores oscuros y olvidados de la motivación humana. El impulso pedagógico basado exclusivamente en la concepción de la humanidad como progreso, o como

${ }^{16}$ Cf. H.-G. Gadamer, Verdad y método. Fundamentos de una hermenéutica filosofica, trad. cast. A. Agud y R. de Agapito, Salamanca, Sigueme, 1975, p. 432. (En adelante citaremos esta obra incluida en el texto con las siglas VM. seguidas del número de página.)

17 E. Severino, Il Giogo. Alle origini della ragione: Esquilo, Milán, Adelphi, 1989. 
apunta Gadamer, en la ilusión de que todo retorna siempre (VM. 434) ha evidenciado ya sus carencias en la aspiración misma de totalidad. La memoria, en su insistencia resignada por la novedad, expulsa y excluye la serenidad simbólica del retornar. La experiencia, de este modo, no se da para siempre sino que se ejecuta cada vez como la primera para desaparecer luego en la memoria. "La experiencia es (...) la experiencia de la finitud humana. Es experimentado en el auténtico sentido de la palabra aquel que es consciente de esta limitación, aquel que sabe que no es señor ni del tiempo ni del futuro" (VM. 433).

En este mismo sentido la propuesta de Mélich de hacer de la experiencia un punto de partida de la ética en general y de la ética pedagógica en particular se alienta en la concepción hermenéutica de que la experiencia no es propiamente un hacer sino un padecer ya que se trata de un saber singular del que nadie nunca nos puede relevar ${ }^{18}$. Son esta precariedad y estas urgencias las que hacen que el hombre no tenga en sus manos, ni lo peor, tampoco pueda creer que las tenga, las condiciones de su existencia. A esto el filósofo alemán Hans Blumemberg lo denomina el "absolutismo de la realidad" ${ }^{19}$. El mito, con su extensión ritual, y la ciencia han pretendido dar cuenta permanentemente de esta obligada implicación, por ello occidente es una muestra ejemplar del carácter defensivo del hombre frente a la contingencia y a la ausencia de fundamento. La educación, la escuela, puede ser definida desde su comportamiento simbólico y ritual ${ }^{20}$ y en buena medida el ritual de sus prácticas y de sus discursos son comprendidos desde esta perspectiva antropológica que la caracteriza como estructura de acogida ante la contingencia ${ }^{21}$, o dicho de otro modo, como mecanismo de defensa y de protección ante el sufrimiento implícito en la natalidad. Aquello que resulte ser lo que nos interpela como real en ese nacimiento permanente que es la existencia no tiene que ver, por tanto, con tener más o menos fortuna epistemológica sino con la incorporación a un mundo y a un lenguaje. La acogida pedagógica en el habitáculo temporal de nuestra historicidad nos proporciona una palabra en la que nos formamos pero al mismo tiempo en la que sentimos nuestra propia ausencia. Por eso buscar y encontrar la palabra, en el magisterio hacer buscar y encontrar la palabra, es siempre una experiencia de limitación. En ello se

\footnotetext{
${ }^{18}$ Cf. J. C. MËLICH, o. c., p. 75 y p. 87.

19 Ibid., pp. 61-62.

20 Ver J. C. MĖLICH, Antropología simbólica y acción educativa, Barcelona, Paidós, 1996.

21 Cf. Ll. DuCH, La educación y la crisis de la modernidad, Barcelona, Paidós, 1997, pp. 15 y ss.
} 
encuentra también el porvenir de la lectura vital. «El que de verdad quiere hablar a alguien — señala Gadamer- lo hace buscando la palabra, porque cree en la infinitud de aquello que no consigue decir y que, precisamente porque no se consigue, empieza a resonar en el otro. Algo de esta sabiduría del balbucir y enmudecer sea tal vez la herencia que nuestra cultura espiritual deba transmitir a la de las próximas generaciones" ${ }^{22}$. Es únicamente en esta esperanza pedagógica tamizada por el padecimiento donde ha de activarse todo tipo de pensamiento cómodamente inmovilizado y desde donde se pueden rescatar verdaderamente los presupuestos de la filosofía gadameriana para la filosofía de la educación. Como «sabiduría del balbucir y del enmudecer» la pedagogía hermenéutica del padecimiento permite superar todo planteamiento inmediatamente positivo sobre el ser y el deber ser del ser humano. El que estemos instalados en nuestra limitación, pero sobre todo su radical reconocimiento ontológico, nos posibilita comenzar la acción balbuciendo y enmudeciendo. En esta disposición epistemológica carente, la filosofía hermenéutica ya no es sólo una respuesta al debate sobre las ciencias sociales y humanas o al debate sobre objetivismos y subjetivismos filosóficos, sino que se hunde incondicionalmente en la cuestión del sentido y de la proyección del sentido. El hecho de no encontrarnos en situación sino de ser situados hace que el fenómeno de la interpretación no sea posterior a cualquier actividad humana sino el propio modo de ser que la configura. Esta universalidad de la hermenéutica, sobre la que Gadamer ha insistido en toda su obra, al determinar toda actividad del saber y del comprender, se convierte en un momento ineludible de las prácticas y los discursos educativos condicionando y enriqueciendo los fenómenos de la transmisión, de la reproducción, del aprendizaje, de la didáctica y el magisterio y del saber en sí mismo. En este momento, en el que nuestra mirada hermenéutica retorna de su tarea reflexiva sobre sí misma y en el que podemos retomar la potencialidad de los planteamientos gadamerianos en el ámbito educativo, es precisamente en el que menos podemos olvidar que es esta suerte de sufrimiento pedagógico que ha brotado de nuestra tentativa reductiva, y no la pretensión epistemológica de ofrecer una alternativa de autocomprensión viable y operativa a las ciencias humanas y en especial a las ciencias de la educación, lo que ha de ofrecer la guía de la parte final de este trabajo.

22 H.-G. GADAMER, "La actualidad de Hölderlin", en Poema y diálogo. Ensayos sobre los poetas alemanes más significativos del siglo XX, trad. cast. D. Najmías y J. Navarro, Barcelona, Gedisa, 1993, p. 12. 


\section{La paideía del lógos hermenéutico}

Cuando Gadamer nos dice que si alguien quiere hablar a alguien de verdad ha de hacerlo buscando en la palabra, no sólo está llenando de contenido dialógico la interacción educativa sino que está manifestando una de las resistencias más radicales a la instrumentalización de las relaciones humanas propia de nuestra cultura. Sin embargo, ahora en el debate sobre la posibilidad real de soportar todo tipo de renovación pedagógica actual sobre una tecnología de la comunicación carente de palabras, lo que sí que nos recuerda esta beligerante resistencia del lógos hermenéutico es que gracias a nuestra ya tematizada carencia del balbuceo no resulta ahora posible olvidar el carácter central del lenguaje en el ser humano en todas sus realizaciones y en especial en la educativa. Toda apertura y toda dinamicidad comprensiva del ser-ahí acontece lingüísticamente y tal centralidad del lenguaje es precisamente la que permite «mediar la esencia historico-finita del hombre consigo mismo y con el mundon (VM. 548). Siendo, tras nuestra reducción, bien conscientes de la raíz última de nuestra lingüisticidad, no resulta tan fácil someter el potencial crítico de la palabra obedeciendo a los intereses amnésicos de los mercados y sus coyunturas con objeto de neutralizar el vínculo esencial entre la cultura y la educación. Es la verdadera huella lingüística de nuestra finitud la que sostiene, según Gadamer, nuestra posibilidad de crecimiento y de ser educados (cf. VM. 149). La narración es el modo en el que reconocemos esta lingüisticidad y de ello se deriva la importancia retórica de la educación, sin embargo en el contexto actual nos narramos siempre desde el simulacro (Baudrillard), ofreciendo un confuso requiebro irónico sobre la forma más extrema de padecimiento, es decir, sobre la virtualidad. Por ello Gadamer reclama el poder de la palabra, porque de este modo el sufrimiento pedagógico se autentifica. De alguna manera, si escuchamos detenidamente hacia dónde han de dirigirse, siempre tentativamente, los desvelos por revincular la palabra con la cultura, estaremos asistiendo, al mismo tiempo, a una propuesta educativa responsable. La invitación nos la hace Gadamer en este breve y significativo fragmento: «La labor de nuestra tradición cultural y una garantía de su integridad, reside en cultivar entre nosotros estas formas excelsas de la palabra: la palabra de la pregunta, que se lleva a sí misma; la palabra de la fábula, que se acredita a sí misma; y la palabra de la reconciliación, que es como la primera y la última ${ }^{23}$. No creemos que pueda

${ }^{23}$ H.-G. GADAMER, "La cultura y la palabra", en Elogio de la teoria. Discursos y articulos, tr. cast. A. Poca, Barcelona, Península, p. 21. 
darse un juego hermenéutico más apropiado y necesario que el pedagógico para que pueda desarrollarse plenamente el contenido de este triple "éxtasis» de la palabra. Tanto en la palabra dialógica del preguntar, a la que aludiremos más tarde, reconociendo siempre sus límites en la tarea permanente de interpretar y de tener que trascender en la interpretación del otro, como en la palabra poética y fabuladora referencia de si misma siempre obligada a seducir en el decir imaginario del tiempo, o como la palabra del perdón y la reconciliación derrotando al olvido ya que es únicamente el otro el que verdaderamente puede remitir a lo que soy por lo que he sido, las tres, nos permiten vislumbrar cómo la pedagogía hermenéutica no puede estructurarse más que sobre el diálogo, la imaginación y la alteridad. Es la centralidad del lenguaje la que plenifica esta proyección en la que nos sitúa nuestra memoria. Intentaremos anticipar en lo que sigue algunas intuiciones sobre la extensión hermenéutica de la educación dejándonos guiar por esta triple tópica de la palabra hermenéutica y pedagógica que nos propone Gadamer.

En alguna medida, podría servirnos para esta labor la categorización de la hermenéutica pedagógica que realiza R. Pagano ${ }^{24}$, ya que él entiende que las tres dimensiones esenciales que se proyectan en este asunto son, en primer lugar, el fenómeno de la interpretación que da respuesta al problema del sentido, en segundo, el fenómeno de la comprensión que surge de la revalorización de la tradición y, por último, la consolidación de la comunicación como el momento esencial de la lingüisticidad y de su extensión ética. Efectivamente, la triple tópica de la palabra pedagógica podría adaptarse a esta categorización y a los sugerentes análisis que Pagano propone en la segunda parte de su libro en lo referido a las claves metodológicas que ofrece la hermenéutica para la pedagogía y para la didáctica. Sin embargo, la intención de nuestro trabajo arranca de presupuestos diferentes y, por ello, nuestra lectura no se puede acomodar a la intención metafísica del autor italiano ${ }^{25}$. Pero además tampoco nos interesa, en este momento de nuestra reflexión, caer en la tentación en la que cae Pagano, a pesar de decir no pretenderlo, de considerar la sutileza aplicativa recuperada por Gadamer como una vía inmediatamente fructifera para la metodología didáctica, tal y como nos quiere hacer ver en la última parte del trabajo dedicado expresamente al tema.

${ }^{24}$ Cf. R. PAGANO, Limplicito pedagógico in H.-G. Gadamer. Riflessiono e spunti per una pedagogia ermeneutica, Brescia, La Scuola, 1999.

25 Ibid., p. 9. 
Frente a ello, nos interesa más situarnos en la órbita del pedagogo holandés Max van Manen, que desde una perspectiva gadameriana ha rehabilitado el tacto para la educación, con las grandes repercusiones que ello tiene para la práctica docente y sustrayéndose inicialmente de cualquier intención metodologista de principio. También nos interesa más la perspectiva de $S$. Gallagher, quien después de hacer una lúcida clasificación de los juegos hermenéuticos contemporáneos identifica la de Gadamer con un tipo de hermenéutica de la cual se pueden extraer grandes conclusiones en el empeño de activar la capacidad autoformativa de la experiencia lectora en sentido amplio. Y también, por último, nos interesan las aportaciones del maestro, pedagogo y filósofo de la educación británico J. Elliott, que al continuar con la concepción procesual y dinámica del currículo de su maestro Stenhouse y desde una activa órbita gadameriana, está ofreciendo un auténtico ejercicio de aplicación hermenéutica para el ámbito de la Investigación-Acción en educación.

En los tres encontramos esta preocupación por la triple tópica de la palabra gadameriana, ya que en los tres encontramos atravesados sus presupuestos: el valor activo de la precomprensión, del preguntar y del diálogo; el valor necesario de la lectura sostenido por la memoria y por la comprensión, que es tacto hermenéutico-pedagógico; y el valor de la reflexión sobre la propia acción como ejercicio permanente de evaluación de la experiencia y de interpretación de la propia acción educativa. Como es natural en el poco espacio que dedicaremos únicamente se ofrecerá una panorámica sobre el asunto sin perjuicio de un ulterior desarrollo.

\section{La rehabilitación de la experiencia educativa como experiencia hermenéutica}

Probablemente la gran aportación de S. Gallagher, al entender la experiencia educativa como experiencia hermenéutica, es que no se concibe la filosofía hermenéutica como un modo o método actual que puede ser aplicado coyunturalmente con más o menos éxito a las tareas docentes. Más bien lo que este autor americano nos propone tiene que ver con una interdependencia de la dinámica educativa con la propia estructura hermenéutica, de tal forma que es la propia experiencia educativa, dada su peculiar naturaleza dialógica, la que puede influir en los desarrollos y procesos del modo que tenemos de entender la experiencia hermenéutica misma. En este sentido, el gran hilo conductor es el lenguaje, ya 
que a través de él no sólo se desarrollan todos los procesos de mediación sino que conseguimos instalarnos en una tradición y en unos límites de demarcación epistemológica dentro del constitutivo fenómeno de la comprensión, dado que ésta no se concibe como un mero acto de abstracción mental. Expresamente nos dice: "Comprometernos con la realidad es comprometernos en un diálogo: aprender es comprometerse con el lenguaje que nos rodea. La realidad misma es interpretada por una comprensión condicionada por el lenguaje. No nos enfrentamos cara a cara con los actos neutralizados. En nuestras proyecciones hermenéuticas nos encontramos con un mundo significativo que no es independiente del lenguaje que utilizamos para expresarlo. Deliberar, argumentar, juzgar, valorar, etc., son todas formas que colocamos en el diálogo con el mundo. Tal diálogo se hace posible a través del lenguaje y en sí mismo constituye el proceso de aprendizaje (...). Aprender no es la recogida de información en una mente aislada. Supone el juego recíproco entre nosotros mismos y las tradiciones que encontramos en nosotros mismos en tanto que seres lingüísticos»" ${ }^{26}$.

Para situar su aportación y enmarcar sus presupuestos gadamerianos Gallagher distingue cuatro líneas en el ámbito de la hermenéutica actual ${ }^{27}$. Por un lado, la conservadora que, muy marcada por la normatividad metodologista de la interpretación, no suele poner en tela de juicio las tradiciones en las que se instala. Aquí se incluyen autores como E. Betti o E.D. Hirsch; en segundo lugar, distingue una hermenéutica moderada, desarrollada sobre todo por Gadamer y Ricoeur, en la que se insiste en la lingüisticidad y la narratividad de la interpretación y el creativo condicionamiento del lenguaje y de la circularidad dialógica de la comprensión. Esta perspectiva, en la que Gallagher se inscribe abiertamente, ofrece según el autor grandes posibilidades para reflexionar sobre la tarea educativa, ya que más que por un objetivismo unidireccional se encuentra sustentada por los principios aplicativos de la razón práctica sobre los que ha de soportarse más adecuadamente la naturaleza cualitativa de lo educativo; la denominada moderación, se alcanza frente a una postura hermenéutica crítica, en tercer lugar, y otra denominada radical, en cuarto. Vinculada a Habermas, la postura hermenéutico-educativa crítica nos habla de principios de comunicación que no pue-

${ }^{26}$ S. Gallagher, Hermeneutics and Education, Nueva York, State University of Nueva York, 1992 , p. 116.

${ }^{27}$ Cf. ibid., pp. 9-11. 
dan ser distorsionables con objeto de poder garantizar el no sometimiento y la emancipación. Autores como Giroux, Bowles y Gintis, Bouedieu-Passeron, etc., podrían quedar enmarcados dentro de estos presupuestos críticos; y por último, distingue una hermenéutica radical que tiene que ver con la permanente desconfianza referida al sentido y a la legitimación inercial de los discursos. El educativo, en este sentido, es especialmente sospechoso por su tendencia universalizadora. Los representantes del pensamiento postmoderno darían cuenta de esta postura.

No sólo el aprendizaje, que se entenderá más que como un proceso de transmisión de saberes y disciplinas tal y como lo entendía la educación tradicional, como un permanente intercambio hermenéutico de interpretaciones y de actualización del sentido, sino también la dimensión ética que se desprende del ejercicio de la libre aplicación de la autonomía con la consiguiente revisión de la normatividad educativa o la reconsideración dialógica del concepto de formación, son algunas de las aportaciones importantes que se desprenden de la interrelación entre las claves de esta hermenéutica moderada con la práctica educativa. M. García Amilburu lo ha resumido muy oportunamente en los siguientes puntos esenciales: 1) Todo tipo de experiencia educativa (lectura, clases, juegos, etc.) está determinada por la estructura circular de la precomprensión; 2) La acción educativa se sustenta en una tradición sobre la que se proyecta un modo de ver el mundo; 3) Toda experiencia educativa es siempre lingüística; 4) Del mismo modo que Gadamer nos hablaba de en qué medida la experiencia hermenéutica nos transforma, Gallagher señala que la educación implica unos movimientos de apropiación y trascendencia con la que se sustrae de la mera productividad; 5) El preguntar es la estructura propia de la experiencia educativa; 6) La experiencia educativa es aplicativa, pero como ya hemos ido considerando, no desde un punto de vista tecnológico sino desde el punto de vista de la significatividad para el sujeto; 6) La educación es autoconocimiento; 8) La experiencia hermenéutico-educativa implica someter a la normatividad al dinámico proceso de acondicionamiento histórico a las circunstancias a través del modelo aristotélico de la phrónesis $^{28}$.

${ }^{28}$ M. ${ }^{2}$ Garcfa AmILBURU, La educacion, actividad interpretativa. Hermenéutica y Filosofia de la Educación, Madrid, Dykinson, 2002, pp. 153-154. 
Sin duda será preciso tener en cuenta esta puesta en funcionamiento de la interrelación hermenéutica-educación que lleva a cabo Gallagher al hacer extensiva la cuestión, ya no sólo del texto a la acción, es decir, la extensión de la lectura a los acontecimientos socioculturales, sino al problema del aprendizaje entendido como una categoría más universal que la de la lectura ${ }^{29}$; pero de igual modo será preciso hacer pasar sus intuiciones por el filtro trágico del debilitamiento donde pueda reconsiderarse la raíz genuina de esa aspiración de universalidad aún presente para lo educativo.

\section{EI tacto hermenéutico-pedagógico}

No parece difícil deducir de la reticencia hermenéutica al metodologismo que una mirada a la educación desde tal perspectiva tenga que estar condicionada por una clara reivindicación de la sensibilidad pedagógica. Max van Manen en sus escritos ofrece una clara intención de desbloquear todos aquellos fenómenos menos objetivadores de la experiencia como la interpretación pedagógica, la situación y el tacto educativo y las relaciones e interacciones dialógicas. Para Van Manen el tacto y la solicitud pedagógica no se encuentran con ninguna regulación previa ${ }^{30}$, el único sometimiento es el de la situacionalidad y el de la finitud histórica. Aquí, el padecimiento hermenéutico-pedagógico deviene compadecimiento y desde tal plataforma se desarrolla la experiencia educativa de la comprensión. Van Manen señala que ula comprensión pedagógica es siempre una especie de comprensión aplicada, (...) se lleva a la práctica mediante lo que podemos llamar 'tacto pedagógico', (...) se interesa por las circunstancias únicas y particulares, (...) no es abstracta, (...) La comprensión pedagógica es en sí misma comprensión práctica: una hermenéutica práctica del ser y del llegar a ser de un niño en una situación determinadas ${ }^{31}$.

Este "momento pedagógico" no está estructurado por una observación cuantitativa, ni por construccionismos éticos, ni por principios teóricos instructivos

${ }^{29}$ Ibid., p. 152.

${ }^{30}$ Recordemos en este sentido que para Gadamer por tacto ha de entenderse «una determinada sensibilidad y capacidad de percepción de situaciones así como para el comportamiento dentro de ellas cuando no poseemos respecto a ellas ningún saber derivado de principios generales». (VM. 45)

31 Cf. M. VAN MANEN, El tacto en enseñanza. El significado de la sensibilidad pedagógica, trad. cast. E. Sanz, Barcelona, Paidós, 1998, pp. 98-99. 
o curriculares, sino en la sintonía entre los agentes y la acción misma. La educación es, de este modo, paradigma de sutileza aplicativa (subtilitas applicandi). Por tanto, más allá de la tecnología educativa y su empeńo por regular sus prácticas se impone la formación del sentido común desde la experiencia. Gadamer, apoyándose en los planteamientos de Vico, nos dice: «El tema de la educación también sería ahora otro: el de la formación del sensus communis, que se nutre no de lo verdadero sino de lo verosímil. Lo que a nosotros nos interesa aquí es lo siguiente: sensus communis no significa en este caso evidentemente sólo cierta capacidad general sita en todos los hombres, sino al mismo tiempo el sentido que funda la comunidad. Lo que orienta la voluntad humana no es, en opinión de Vico, la generalidad abstracta de la razón, sino la generalidad concreta que representa la comunidad de un grupo, de un pueblo, de una nación o del género humano en su conjunto. La formación de tal sentido común sería, pues, de importancia decisiva para la vida» (VM. 50). Desde esta intención la fusión de horizontes de una rehabilitada experiencia educativa implica el proceder con el tacto al que nos invita el obrar adecuadamente en cada situación concreta, es decir, el desarrollo de la acción desde el sentido común. Para Van Manen, será la «influencia pedagógican la que proporcione la activación del reposo reflexivo en el obrar: ese «educarse" del que Gadamer nos habló en un breve y reciente ensayo y que, evidentemente, nada tiene que ver con un embelesamiento autista y prácticamente todo con un reconocimiento de la pertenencia a la que ya nos hemos referido. Cuando se nos propone, entonces, este ejercicio de reflexividad educativa se nos está diciendo que la formación tiene sentido, aun no teniendo dirección, sólo si se permanece en el camino, es decir, en el espacio dialógico de la memoria compartida. En estos principios, sin duda, se sustenta la vinculación expresa que Van Manen realiza de su concepto de influencia con el de alteridad debido a su carácter esencialmente mediador. El espacio común del logos y de la memoria en el que se desarrollan todas las acciones comprometidas con la solicitud dialógica de la comprensión hace que a través de esta influencia educativa la recursividad del otro forme parte del desarrollo propio. «La influencia — señala expresamenteconnota la actitud abierta que muestra un ser humano respecto a la presencia de otron ${ }^{32}$. Se puede pensar en qué medida es dado rescatar los planteamientos más originarios de la emoción pedagógica entre maestro y alumno si ninguno de los dos horizontes son prioritarios; el uno, por motivo de la violencia metafísica del

${ }^{32}$ M. VAN MANEN, o. c., p. 32. 
saber y de las disciplinas que de ella se desprenden, en el que la transmisión únicamente se basa en el rigor memorístico y reproductor (escuela tradicional); o el otro, por la instrumentalización tecnológica y psicológica del aprendizaje que hace del alumno un virtual centro de legitimación de la autonomía ciudadana para las democracias autosatisfechas. El espacio común del lógos hermenéutico es un espacio de carencias y de encuentros en el que se dinamiza la reciprocidad de la formación y del deseo, en este caso, como deseo de que el saber ofrezca la ilusión del sentido.

\section{La reflexión-acción hermenéutico-educativa}

Sin duda, detrás de todo este torbellino retórico-pedagógico se encuentra la rehabilitación de la filosofía práctica y, por extensión, del desdibujamiento de los límites entre teoría y praxis. Una de las consecuencias del debilitamiento ontológico era la de la descarga de la unidireccionalidad teórica y la de la fragmentaria actualización de todos los discursos en su transversalidad. Todos los síntomas conocidos en la época contemporánea sobre la movilización de la verdad y, con ella, de los saberes, han ido dotando a las distintas ciencias humanas de una reconsideración de raíz. En educación, las teorías curriculares son las que se ven más significativamente afectadas, ya que, en tanto que gran matriz del hecho educativo, la consideración curricular pasa de regirse por principios categorizantes en su linealidad ahistórica a regirse por la idea de la procesualidad de toda práctica y de la siempre abierta incorporación del saber en sus agentes, en los tiempos y en los espacios. Siguiendo esta perspectiva y a Stenhouse, uno de sus mentores más importantes, la propuesta de Elliott quiere ser, por una parte, una tarea de interpretación interactiva de los profesionales de la educación sobre sus propias prácticas y, por otra, una empresa moral en la que se explicite la realización práctica de los valores. En ambas dimensiones destaca, a nuestro entender, el presupuesto sustentante de la filosofía hermenéutica como impulso de renovación pedagógico-curricular en nuestros días.

Elliott quiere reconstruir en su totalidad la tradición de investigación iniciada por Aristóteles sin obviar el saber práctico y cualitativo en favor del saber técnico, instrumental, eficaz y mensurable. Para ello, desde la facticidad de la comprensión, se habilita la dimensión personal de la comprensión interpretativa de la contingencia a partir de la energía eventual de los acontecimientos históricos y de las prácticas, en este caso educativas, para hacer que la reflexión se realice de for- 
ma simultánea a la praxis. La praxis así se revitaliza, ya que esencialmente tiene que ver con lo viviente, con todo aquello que lleva una determinada forma de vida y, además, en el caso concreto de la vida humana, lo más característico según Gadamer es precisamente la ejecución de la vida, es decir, la elección. La phrónesis, de este modo, es ahora entendida como un caso paradigmático de practicidad vital y linguística. Sobre la phrónesis no se puede especular, ni pretender definición alguna a priori. Más bien, como cree John Elliott, resulta ser el modo apropiado de constatar críticamente en la ejecutividad misma de la comprensión el modo en que operan los principios que regulan la acción. "La teoría de la comprensión de Gadamer, señala Elliott, rechaza que los valores y creencias que subyacen a nuestros principios prácticos puedan ser criticados de forma adecuada desde un punto de vista no relacionado de manera directa con la formación de un juicio práctico, porque la phrónesis siempre es constitutiva de la búsqueda de la comprensión en el campo humano. De ello se deduce que, así como la phrónesis es el contexto en el que los principios prácticos se comprueban y desarrollan en relación con las situaciones particulares, es, por tanto, el contexto en el que los valores y creencias subyacentes se ponen de manifiesto y se someten a crítica. La comprobación de los principios prácticos y la crítica de los valores y creencias que los sustentan constituyen dos aspectos de un proceso unificado de reflexión» ${ }^{33}$. Así las cosas, la práctica educativa concreta es un permanente ejercicio de reflexión y reinterpretación en el que los valores se encuentran siempre abiertos. La mejora, o la simple actualización, viene condicionada de forma ineludible por la traducción contextual que se realiza de ese valor que anima la práctica y de la carga de tradición que consolida la narratividad dialógica de los agentes. Evidentemente, esta mirada cualitativa sobre el análisis pierde los miedos de la neutralidad científica a que la subjetividad, que precisamente constituye las prácticas vitales de la educación, empañe los análisis y la propia posibilidad de dominio sociopolítico implícita en ellos mismos. Por eso A.I. Pérez Gómez señala que frente a «los modelos neoconservadores en educación que pretenden reimplantar en la actualidad el principio de la eficacia y de la primacía de los resultados tangibles sobre el valor educativo de los procesos, Elliott defiende con énfasis la necesaria reflexión conjunta de fines y medios y el análisis crítico de los instrumentos y procedimientos educativos» ${ }^{34}$.

${ }^{33}$ J. ElliotT, La investigación-acción en educación, trad. cast. P. Manzano, Morata, Madrid, 1997, 3.2 ed. p. 119.

${ }^{34}$ A. I. PÉREZ GOMEZ, "Comprender y enseñar a comprender. Reflexiones en torno al pensamiento de J. Elliott», introducción a J. ELLIOTT, o.c., pp. 12-13. 
Desde tales presupuestos epistemológicos y culturales, los nuevos valores del movimiento de investigación-acción educativa hacen tambalearse la parcialidad cientifista de la teoría en la tarea educativa y el carácter aséptico de una metodología sorprendentemente separada de la acción misma. Mantener el dilema teoria-praxis presenta, en opinión de Elliott, la interesada manifestación del control del poder tecnológico sobre el saber a través del manejo implícito de la práctica docente en las aulas. Por ello, el desdibujamiento de límites en la acción reflexiva implica un componente crítico indudable en tanto que la aplicación hermenéutica de las prácticas culturales y educativas se readueñan de sí mismas. Los agentes se convierten en creadores de sí mismos, con lo cual el estado de autonomía creativa en el que se enmarca el juego dialógico-educativo permite resaltar la rehabilitación del contenido ético de la formación humana, de la socialización, de la legitimidad de las transmisiones de la cultura a la que se pertenece y del discurso inevitablemente narrativo en el que se desarrolla. En este sentido, al resaltar el hecho de la narratividad de la investigación-reflexión-acción en sus múltiples variantes, se destaca el carácter lingüístico e interpretativo que anima todos estos procesos de comprensión pedagógica ${ }^{35}$. Elliott no duda en personificar y humanizar la intención ontológica que anima la reflexión heideggeriana y gadameriana sobre la facticidad de la comprensión, es decir, sobre que la comprensión es nuestro modo de ser de hecho. En opinión de Elliott, el propio Gadamer «considera que su punto de vista de la relación entre comprensión, interpretación y aplicación es válido para toda investigación relacionada con la comprensión de las personas. En esencia, Gadamer sostiene que las formas de comprensión que tienen como objeto propio a las personas proporcionan un conocimiento moral que guía la elección y el juicio de las situaciones prácticas concretas ${ }^{36}$. Esta consideración práctica y, en sí misma, la extensión ética del fenómeno de la comprensión es el apropiado subsuelo sobre el que cimentar un espacio liminar habitable, un espacio de interpretación, en el que desaparece el corte entre teoría y praxis en tanto que interpretar en el comprender es al tiempo reflexión y aplicación, es contextualización semántica de la acción en su ejecución.

35 Sólo como muestra, aunque especialmente significativa, de la importante bibliografía que comienza a desplegarse en torno a la reciente vinculación entre narratividad y educación, me permito destacar el libro de BOLIVAR, DOMINGO y FERNANDEZ La investigación biográfico-narrativa en educacion. Enfoque y metodologia, Madrid, La Muralla, 2001.

${ }^{36}$ J. ELLIOTT, o. c., p. 115. 
Dos cuestiones importantes se desprenden de lo que venimos diciendo: la revisión del modo en que entendemos el aprendizaje, por una parte, y la labor docente, por otra. Sobre lo primero habría que decir que el carácter sintético de la reflexión en la práctica implica rehabilitar abiertamente aquellos conceptos de raíz fenomenológica de situación y horizonte mediante los cuales la interacción histórica con el mundo se presenta como elemento constituyente necesario de la subjetividad. El carácter contextual, por tanto, de la acción reflexiva se aleja de un cognitivismo trascendental y, por ello, se encuentra más cercano del giro culturalista de la psicología del aprendizaje emprendido por autores como L. Vygotsky o J. Bruner. "La enseñanza», señala Elliott, "deja de considerarse como un proceso de adaptación o acomodación de la mente a las estructuras de conocimiento. Se contempla, en cambio, como un proceso dialéctico en el que el significado y la pertinencia de las estructuras se reconstruyen en la conciencia históricamente condicionada de los individuos cuando tratan de dar sentido a sus "situaciones vitales". La mente "se adapta con" en vez de "adaptarse a" las estructuras de conocimiento" ${ }^{37}$. Esto, aparte de evidenciar el rechazo de todo tipo de idealismo pedagógico, pone a las claras que el carácter comunicativo del sentido necesita también reconsiderar el magisterio desde perspectiva hermenéutica. Consideremos el asunto brevemente.

Poniendo en expresa relación el concepto gadameriano de autoridad, rehabilitado de las reticencias ilustradas contra la memoria, con una foucaultiana genealogía contemporánea del poder que pone en evidencia las sutiles prácticas neoliberales por el control del saber, Elliott reivindica la inherente capacidad crítica de la aplicación educativa: En primer lugar, contraponiendo el "poder educativo" al "poder disciplinario". Mientras que en el poder disciplinario, de forma tradicional explícitamente y en nuestros días veladamente, son los sujetos pasivos discentes los que otorgan la autoridad al docente atendiendo a la legitimidad que le confiere a éste, en unas ocasiones, un orden inamovible, violento $y$ unidireccional del saber-verdad $y$, en otras, la sofisticada exigencia moldeadora del mercado de trabajo, el poder educativo recualifica la autoridad a partir del permanente y procesual autorreconocimiento de las partes entre sí. Este hecho, en segundo lugar, hace que al mantenerse la calidad de la acción educativa some-

${ }^{37}$ J. ELLIOTT, El cambio educativo desde la investigación-acción, trad. cast. P. Manzano, Madrid, Morata, 1996, 2. ${ }^{\text {ed., p. } 23 .}$ 
tida a permanente consideración por parte de todos los agentes participantes y ser la propia actividad vital de aprendizaje la que permite a los sujetos saberse y adueñarse de sí mismos, la situación manifiesta un determinado ejercicio de poder en el que la situación se consigue controlar sin que se tenga que "tomar» el control. Como señala Elliott: «Mediante la investigación-acción educativa, los profesores transforman el ambiente de aprendizaje (currículos, métodos de enseñanza y carácter de la escuela) en uno que permita a los alumnos descubrir y desarrollar sus poderes y capacidades. Al crear el poder educativo, la investigación-acción no sólo capacita profesionalmente a los profesores, sino también a los alumnos» ${ }^{38}$. Es decir, que a través de este tipo de práctica docente autónoma la evaluación-reflexión no es ninguna agresión externa sino el modo mismo de su realización.

\section{Consideración final}

Nada ha de hacernos olvidar que este talante ético de la experiencia que quiere rescatar la hermenéutica en el ámbito educativo es únicamente nuestro retorno, nuestra llegada. Sabemos bien que nunca partiremos y que la cesura del padecer nos imposibilita esa trascendencia con la que siempre se ha querido seducir a la pedagogía. Sólo en la escisión y en la diferencia, sólo habitando en el límite, nos recuperamos como deseo y, por tanto, como seres educandos.

${ }^{38} \mathrm{~J}$. ELLIOTT, "Saber, poder y evaluación de los docentes", en W. CARR, Calidad de la enseñanza e investigación-acción, trad. cast. P. Manzano, Sevilla, Díada, 1998, 3. ${ }^{2}$ ed., p. 173. 